\title{
GMR
}

\section{Molecular cloning and expression analysis of heat shock protein 20 (HSP20) from the pearl oyster Pinctada martensii}

\author{
Q.N. Lei, Y.Y. Wu, H.Y. Liang, Z.X. Wang, Z. Zheng and Y.W. Deng \\ Fisheries College, Guangdong Ocean University, Zhanjiang, China \\ Corresponding author: H.Y. Liang \\ E-mail: zjlianghy@126.com
}

Genet. Mol. Res. 15 (2): gmr.15028799

Received May 16, 2016

Accepted June 3, 2016

Published June 24, 2016

DOI http://dx.doi.org/10.4238/gmr.15028799

\begin{abstract}
Small heat shock proteins (HSPs) are molecular chaperones with ATP-independent properties. They are involved in a variety of physiological and stress processes. In this study, the full-length HSP 20 (HSP20) from Pinctada martensii, designated as PmHSP20, was obtained from hemocytes using rapid amplification of cDNA ends technology. The PmHSP20 cDNA was 952 bp in length, containing an open reading frame of $534 \mathrm{bp}$ that encoded 177-amino acid residues, with an isoelectric point of 5.86 and molecular weight of $20.24 \mathrm{kDa}$. The sequence of this deduced polypeptide contained typical structure and function domains conserved in the HSP20 family, providing evidence that PmHSP20 belongs to the HSP20 family. The PmHSP20 mRNA expression levels were detected in various tissues of $P$. martensii and in hemocytes after challenges with the bacteria Vibrio harveyi and lipopolysaccharide (LPS) using quantitative realtime polymerase chain reaction amplification. The results indicated that PmHSP20 is constitutively expressed in all tissues tested and might be involved in the immune response. The upregulation of PmHSP20 after $V$. harveyi and LPS challenge suggests that PmHSP20 plays an important role in anti-bacterial immunity. Studies on PmHSP20 are a
\end{abstract}


valuable resource to further explore the immune system in pearl oysters and might enhance our knowledge of molluscan innate immunity.

Key words: Heat shock protein 20; Pinctada martensii; Cloning; Expression; Bacterial challenge

\section{INTRODUCTION}

Heat shock proteins (HSPs) are ubiquitously expressed and phylogenetically conserved stress proteins existing in all organisms (Caspers et al., 1995). They play an important role during potentially deleterious stress conditions (Hartl, 1996; Jolly and Morimoto, 1999; Feder and Hofmann, 1999; Kregel, 2002). Many stresses, such as elevated temperatures, altered pH, and oxygen deficit impair the establishment of correct protein structures and may result in the disassembly of certain already structured proteins. HSPs are molecular chaperones, which bind to partially denatured proteins to impede their degradation, contributing to the refolding of these proteins depending on ATP after removal of the stress trigger and facilitating their elimination when they become irreversibly damaged (Thomas et al., 2005; Sun and MacRae, 2005). Incremental HSP expression is regulated at various levels such as RNA synthesis, mRNA stability, and translation efficiency (Mahmood et al., 2010). In recent years, proteins with immunological functions have received increasing amounts of attention; thus, focus has been placed on HSPs, which are potent activators of the innate immune system in all animals (Bezemer et al., 2012).

Based on their molecular mass, HSPs are divided into five families: HSP60, HSP70, HSP90, HSP100, and the small heat shock proteins (sHSPs) (Schlesinger, 1990). sHSPs are a group of proteins that consist of a conserved $\alpha$-crystalline domain and variable $\mathrm{N}$ - and $\mathrm{C}$-terminal extensions. Their molecular weights range from 12 to $43 \mathrm{kDa}$ (Mahmood et al., 2010). Notably, increasing numbers of sHSP functions have been generated along with their evolution. sHSPs have been verified to participate in various physiological processes such as actin and intermediate filament dynamics (Wieske et al., 2001; Quinlan, 2002), cellular stress resistance (Landry et al., 1989), life span (Wood et al., 2010), membrane fluidity (Tsvetkova et al., 2002), and disease prevention (Mackay et al., 2003; Selcen and Engel, 2003; Evgrafov et al., 2004). sHSPs comprise multiple specific protein families; in this study, the HSP20 family, which, as the name implies, have an apparent molecular mass of $20 \mathrm{kDa}$, are of particular interest. It has been reported that HSP20 has a basic function in the cellular physiology of the stages of erythrocyte infection. Specifically, it has been implicated in the immediate response to pathological events, the extracellular regulation of platelet functions (Gusev et al., 2005), and in cardioprotection (Islamovic et al., 2007). Consistent with this, the ability of HSP20 to strengthen the endurance of fishery animals to disease is becoming clear (Wan et al., 2012).

Pinctada martensii is an important species of mariculture mollusc in South China owing to its economic value. It is primarily cultured to develop the pearls that are known as "South China Sea Pearls" (Zhao et al., 2012). However, a high mortality in juvenile, mother, and operational cultured pearl oysters has been frequently observed in recent years (Wang et al., 2011), resulting in a severe reduction in seawater pearls (Wang et al., 2009). To date the cause of the mass oyster mortalities has not been elucidated; however, it has been suggested that the causes are connected with multiple factors such as the degradation of water quality, pathogens, and stock degeneration caused by inbreeding (Song et al., 2006). 
Monitoring the response pattern of pearl oysters to environmental challenges might help us to further understand the stress resistance mechanisms in pearl shells, provide assistance in determining appropriate biomarkers to assess environmental impact, and establish treatment strategies for disease control (Wang et al., 2009). To date, several HSP20 gene sequences isolated from mollusc species have been identified, analyzed, and made available in GenBank, including those of Cyclina sinensis (AET13647.1) and Meretrix meretrix (AFK80359.1) (Li et al., 2013). However, no information is available on the transcriptional level expression of HSP20 in P. martensii under bacterial challenge and lipopolysaccharide (LPS) stimulation. Accordingly, the objective of this research was to obtain HSP2O cDNA from P. martensii and to investigate its gene expression patterns in different tissues and its temporal expression after Vibrio harveyi challenge and LPS stimulation. The data presented here identify and characterize HSP20 in P. martensii and suggest a role for HSP20 in the immune response of this organism.

\section{MATERIAL AND METHODS}

\section{Animals and sample collection}

Adult $P$. martensii samples obtained from Liushagang, Zhanjiang, and Guangdong in China were approximately two years of age. The pearl oysters were cultured in recirculating seawater of $25^{\circ}$ to $27^{\circ} \mathrm{C}$ for 3 to 5 days prior to the experiment. For the analyses of gene expression in different tissues, the hemocytes, mantle, gill, adductor muscle, foot and hepatopancreas were collected from healthy pearl oysters and then stored immediately in liquid nitrogen. Among these tissues, the hemocytes were used for quantitative polymerase chain reaction (qPCR) expression analyses.

\section{RNA extraction and preparation of cDNA}

Total RNA was extracted from all isolated tissues using TRIzol (Invitrogen, Carlsbad, CA, USA) referring to the manufacturer manual. A $1 \%$ agarose gel was used to determine the integrity of the RNA. RNA quantity and concentration were measured using a ND1000 spectrophotometer (Thermo, Waltham, MA, USA). cDNA was synthesized following the instruction of the M-MLV reverse transcriptase kit (TaKaRa, Otsu, Japan). The cDNA was used as the template for qPCR.

\section{PCR and cloning of PmHSP20 cDNA}

We applied 5'/3'-rapid amplification of cDNA ends (RACE) to obtain the full-length cDNA of PmHSP20 using the SMART RACE cDNA amplification kit (Clontech, Kusatsu, Japan). Specific primers were designed based on the nucleotide sequences of the HSP 20 cDNA fragment obtained from the transcriptome of $P$. martensii previously constructed in our laboratory (Zhao et al., 2012). Table 1 shows the primers utilized in the current experiment.

In the outer PCR, the template was the RACE cDNA. The outer amplified product was then used as the template for the inner PCR. PCR cycling conditions were as follows: $94^{\circ} \mathrm{C}$ for $5 \mathrm{~min} ; 30$ cycles of $94^{\circ} \mathrm{C}$ for $30 \mathrm{~s}, 68^{\circ} \mathrm{C}$ for $30 \mathrm{~s}$, and $72^{\circ} \mathrm{C}$ for $1 \mathrm{~min}$; and $72^{\circ} \mathrm{C}$ for $10 \mathrm{~min}$. 
Table 1. Primers utilized in this experiment.

\begin{tabular}{l|l|l}
\hline Primer & Sequence (5'-3') & Application \\
\hline 3'-inner & GGAAACACGAGGAGAAACAGGACGAACA & Inner PCR \\
\hline 3'-outer & TTCCCGACCCCTAGCAGAATTTCAA & Outer PCR \\
\hline 5'-inner & TTCCCTGAGATGACCACTCTATTGTCCACTACTT & Inner PCR \\
\hline 5'-outer & CAGTTTTGGGGCGGAGACAGATAGCAC & Outer PCR \\
\hline NUP & AAGCAGTGGTATCAACGCAGAGT & Outer PCR \\
\hline UPM-long & CTAATACGACTCACTATAGGGCAAGCAGTGGTATCAACGCAGAGT & Inner PCR \\
\hline UPM-short & CTAATACGACTCACTATAGGGC & Inner PCR \\
\hline GAPDH-F & GCAGATGGTGCCGAGTATGT & qRT-PCR \\
\hline GAPDH-R & CGTTGATTATCTTGGCGAGTG & qRT-PCR \\
\hline HSP20-F & CTGTTTTGGTGAGGGGAAGG & qRT-PCR \\
\hline HSP20-R & CTGGGGAGAAATGGGATACG & qRT-PCR \\
\hline M13-F & CGCCAGGGTTTTCCCAGTCACGAC & Colony PCR \\
\hline M13-R & AGCGGATAACAATTTCACACAGGA & Colony PCR
\end{tabular}

\section{DNA sequencing and bioinformatics analysis}

The PCR products of the 5'- and 3'-ends were cloned as above, purified using GeneJET PCR purification kit (Thermo), inserted into the pMD-18T vector (TaKaRa), and then sequenced. All the obtained sequences were analyzed using the Basic Local Alignment Search Tool (BLAST) available at the National Center for Biotechnology Information (NCBI; http://www.ncbi.nlm.nih.gov/). The PmHSP20 open reading frame (ORF) was obtained using the ORF Finder tool (http://www.ncbi.nlm.nih.gov/gorf/orfig.cgi). The molecular weight and theoretical isoelectric point were analyzed using a ProtParam tool (http://web.expasy. org/cgi-bin/protparam/protparam). The online tools SMART (http://smart.embl-heidelberg. de/) and PROSITE (http://prosite.expasy.org/) were applied to predict the protein domains and functional sites, respectively. MEGA 6.0 software was applied in the cluster analysis of PmHSP20.

\section{Stress experiments under two different conditions}

For the bacterial challenge experiment, 108 pearl oysters were split at random into two groups. The experimental group was intramuscularly injected with $100 \mu \mathrm{L} V$. harveyi at 1 $\mathrm{x} 10^{7}$ cells $/ \mathrm{mL}$, whereas the control group was injected with $100 \mu \mathrm{L}$ phosphate buffered saline. A total of six post injection time points, $0,2,4,6,8$, and $16 \mathrm{~h}$, were selected for expression analysis.

For LPS stimulation, 144 pearl oysters were split at random into two groups. The LPS challenge group was intramuscularly injected with $100 \mu \mathrm{L}(10 \mu \mathrm{g} / \mathrm{mL})$ LPS diluted with phosphate buffered saline. The treatment method of the control group was same as that in the bacterial challenge experiment. A total of seven time points, $0,2,4,6,8,12,16$, and $24 \mathrm{~h}$ after injection were selected.

Nine pearl oysters were randomly selected at each time point for analysis.

\section{Real-time qPCR analysis}

Real time qPCR was performed using the $\mathrm{SYBR}^{\circledR}$ Select Master Mix Kit (Life Technologies, Carlsbad, CA, USA) following manufacturer protocol and was carried out on the Applied Biosystems 7500 Real-Time system (Foster City, CA, USA). The quantity of each 
PmHSP20 mRNA was calculated as previously described via the $2^{-\Delta \Delta \mathrm{Ct}}$ method (Livak and Schmittgen, 2001). Additionally, the results were normalized to glyceraldehyde-3-phosphate dehydrogenase $(G A P D H)$.

\section{Statistical analysis}

The qPCR data were analyzed using SPSS 19.0 (IBM, Armonk, NY, USA). The Tukey honestly significant difference (HSD) test was used to determine differences among the treatments. $\mathrm{P}$ values less than 0.05 were considered to be statistically significant.

\section{RESULTS}

\section{Characterization of $P m H S P 20$ cDNA and protein sequence}

Specific primers for PmHSP20 (Table 1) were designed based on the 534-bp unigene sequence annotated as HSP2 0 from the $P$. martensii transcriptome database. One pair of nested primers was designed to clone the $5^{\prime}$ and $3^{\prime}$ nucleotide sequences using $5^{\prime}$ - and $3^{\prime}$-RACE technology, respectively. This resulted in the generation of two fragments of 437 and $617 \mathrm{bp}$, respectively. The integrated PmHSP20 cDNA reaching a length to $952 \mathrm{bp}$ was obtained by overlapping the fragments. Sequencing and various bioinformatics techniques as described in the Method section allowed further investigation of this polynucleotide. The data suggest that the complete PmHSP20 cDNA contains a 5'-untranslated region (UTR) of $347 \mathrm{bp}$, an ORF of $534 \mathrm{bp}$, and a 3'-UTR of $68 \mathrm{bp}$, encoding a 177 amino acid polypeptide. The 3'-UTR contained a poly (A) tail of $26 \mathrm{bp}$ and a typical polyadenylation signal (aataaa). The cDNA sequence has been submitted to GenBank and assigned the accession No. AJK26930.1. The deduced amino acids sequence of PmHSP20 consisted of the characteristic HSP20 family motifs predicted by the SMART program (Figure 1).

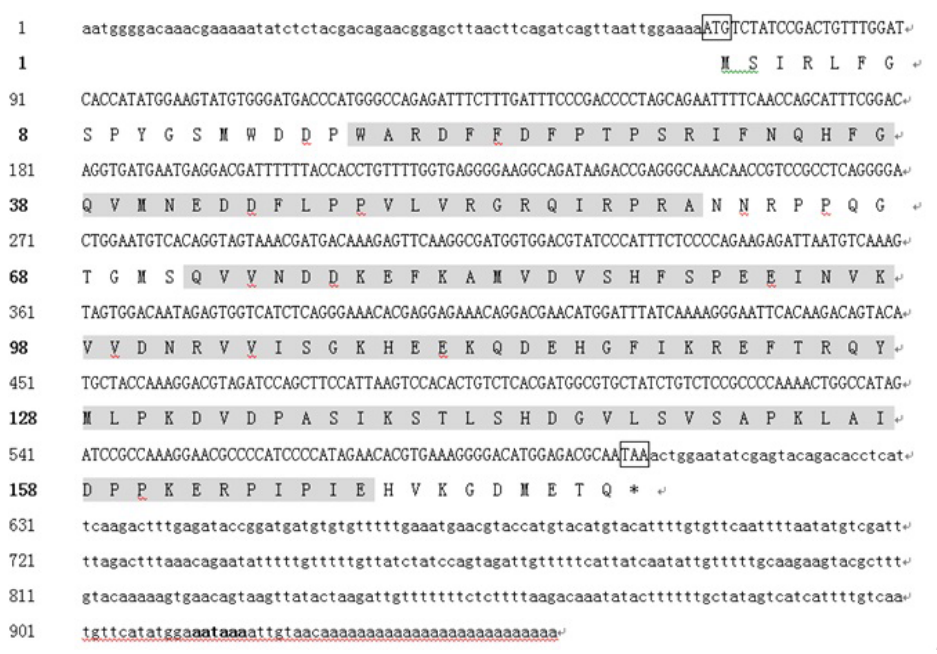

Figure 1. Nucleotide and amino acid sequences of PmHSP20. The initiation codon (ATG) and the stop codon (TAA) are boxed. The putative polyadenylation signal (aataaa) is in bold. The amino acid residues shaded gray represent the crystallin motif and the HSP20 domain, respectively. 


\section{Homology analysis of PmHSP20}

The protein sequence of PmHSP20 demonstrated resemblance with HSP20s of other animals. It shared the highest identity (52\%) with HSP20 from the spider Stegodyphus mimosarum. Additionally, 47\% identity was shown with HSP20 from the nematode Trichinella spiralis, $46 \%$ with the wasp Ceratosolen solmsi marchali, and $45 \%$ with the coelacanth Latimeria chalumnae. Alignment with these proteins showed that most of the identities were located in the characteristic $\alpha$-crystallin domain (Figure 2).
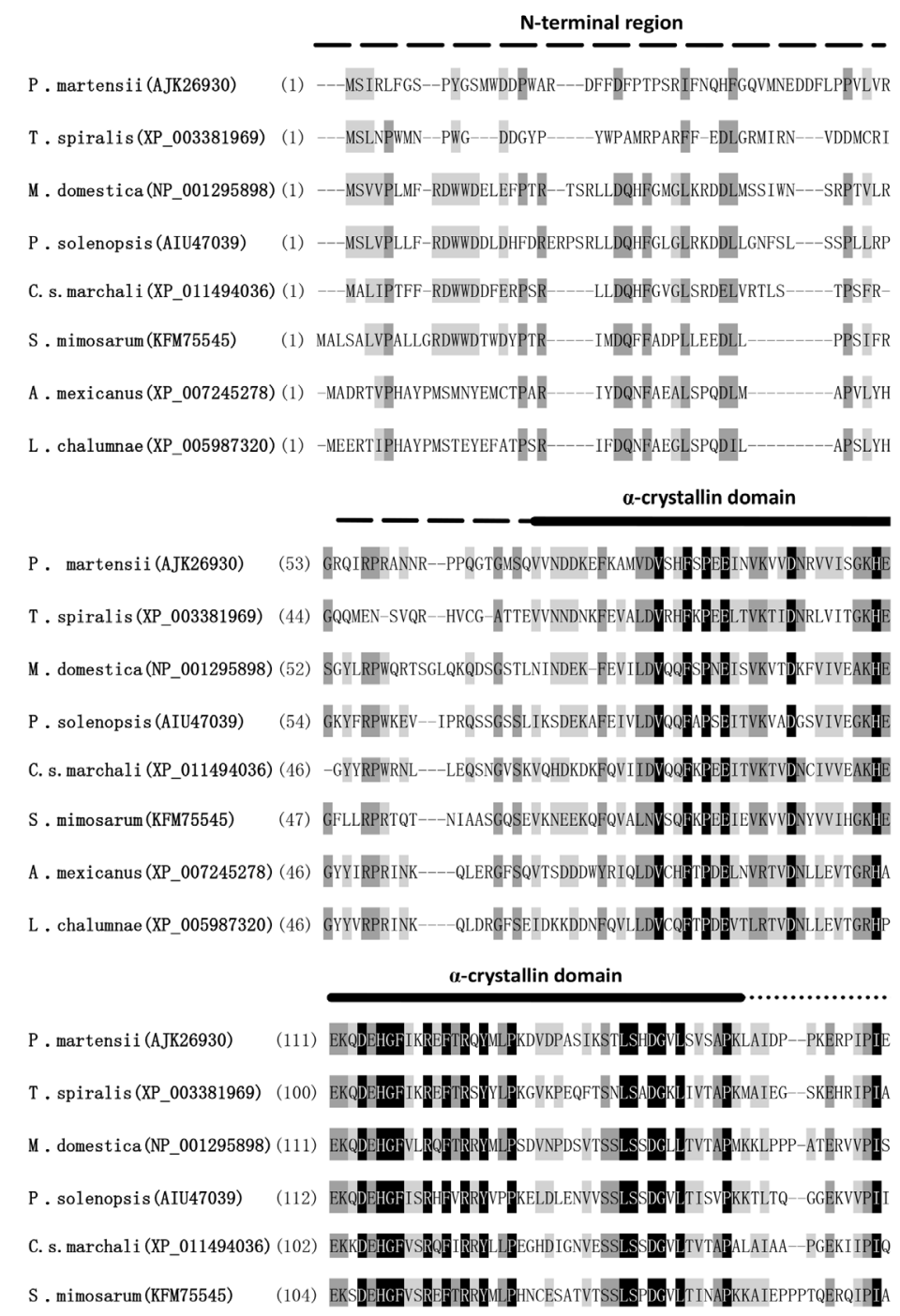

Figure 2. Alignment of HSP20 protein sequences from Pinctada martensii and other invertebrate species. The highly conserved $\alpha$-crystallin domain is marked using a bold black line. The data further show that the N- and C-terminal regions are variable. 
A neighbor-joining phylogenetic tree was built in order to analyze the evolutionary relationship of PmHSP20 with other HSP20 (Figure 3). According to phylogenetic taxonomy, the tree was divided into different clades such as fish, mammals, arthropods, and mollusca. PmHSP20 belongs to the mollusca HSP20 subgroup. The relationships presented in the phylogenetic tree conformed to traditional taxonomy.

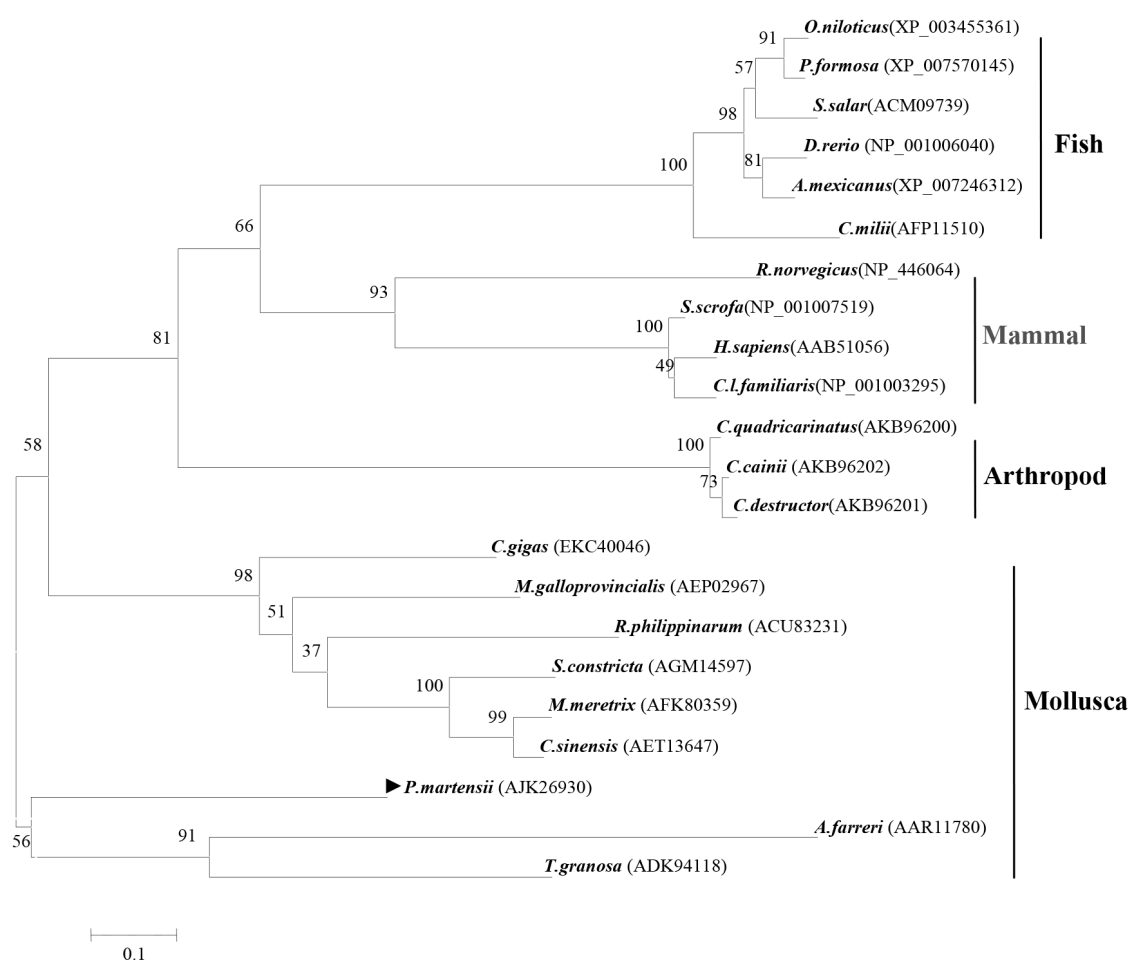

Figure 3. Phylogenetic analysis of PmHSP20. A phylogenetic tree of HSP20 was built using the neighbor-joining method through the program MEGA 6.0 based on the protein sequences of different species. The percentage bootstrap values are indicated by numbers at the branch points.

\section{Quantitative analysis of PmHSP20 gene expression in the sampled tissues}

Real time qPCR was conducted to determine the expression of PmHSP20 mRNA in all sampled tissues. Samples were normalized to the expression of an internal reference, $G A P D H$. The highest expression was detected in the hepatopancreas, which is involved in the defense system of mollusks, whereas a relatively lower expression level was determined in the adductor muscle, hemocytes, gill, and foot (Figure 4).

\section{Temporal expression pattern of PmHSP20 after $V$. harveyi challenge and LPS stimulation}

To further investigate the function of $P m H S P 20$ in the immune response, we analyzed the temporal expression of the PmHSP20 mRNA in hemocytes after $V$. harveyi injection using 
real time qPCR. PmHSP20 expression levels were upregulated and reached a maximum level at $2 \mathrm{~h}$ post-infection $(1.74$-fold, $\mathrm{P}<0.05)$, then fell to their lowest level at $6 \mathrm{~h}$. From 6 to 16 $\mathrm{h}$, the expression of PmHSP20 elevated gradually but significantly at each time tested and peaked at $16 \mathrm{~h}(1.44$-fold, $\mathrm{P}<0.05)$. Thus, PmHSP20 expression in hemocytes is significantly upregulated after infection by $V$. harveyi (Figure 5).

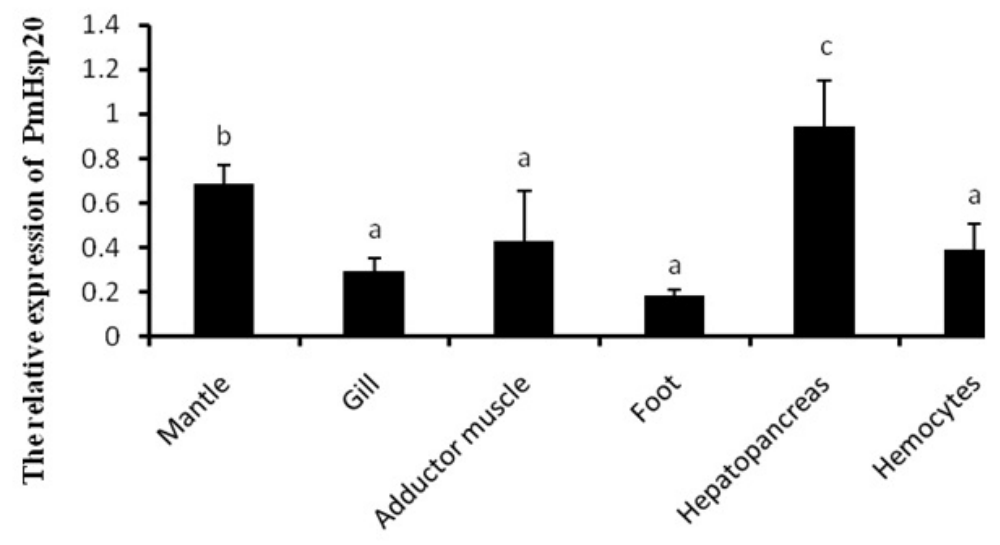

Tissues

Figure 4. Expression patterns of PmHSP20 mRNA in all sampled tissues. The Pinctada martensii GAPDH gene was used as a reference control. Significant difference is indicated by different letters $(\mathrm{P}<0.05)$.

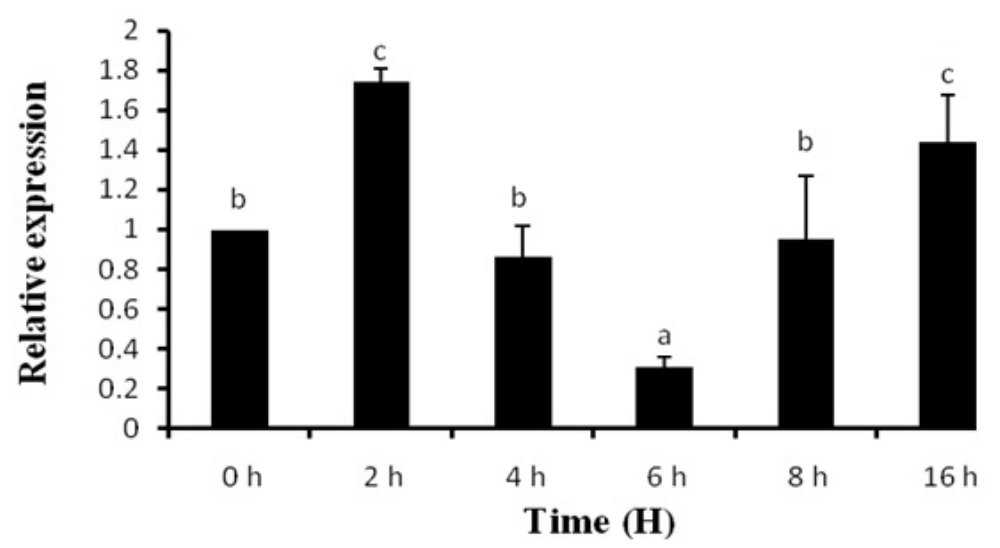

Figure 5. Expression patterns of PmHSP 20 mRNA after Vibrio harveyi challenge. Real time qPCR was performed using cDNA samples generated from hemocytes $0,2,4,6,8$, and $16 \mathrm{~h}$ post-infection. Pinctada martensii GAPDH was used as an internal reference. Significant difference is indicated by different letters $(\mathrm{P}<0.05)$.

PmHSP20 gene expression after LPS challenge was also monitored. The expression of PmHSP20 elevated significantly and reached a peak value at $2 \mathrm{~h}$ post-injection (2.68-fold, $\mathrm{P}$ $<0.05$ ), then fell to its lowest level at $6 \mathrm{~h}$. From 6 to $24 \mathrm{~h}$, the amount of PmHSP20 transcripts heightened gradually at each time tested and peaked at $12 \mathrm{~h}(1.65$-fold, $\mathrm{P}<0.05)$. Subsequently, the expression of PmHSP20 decreased gradually and returned to the original level (Figure 6). 


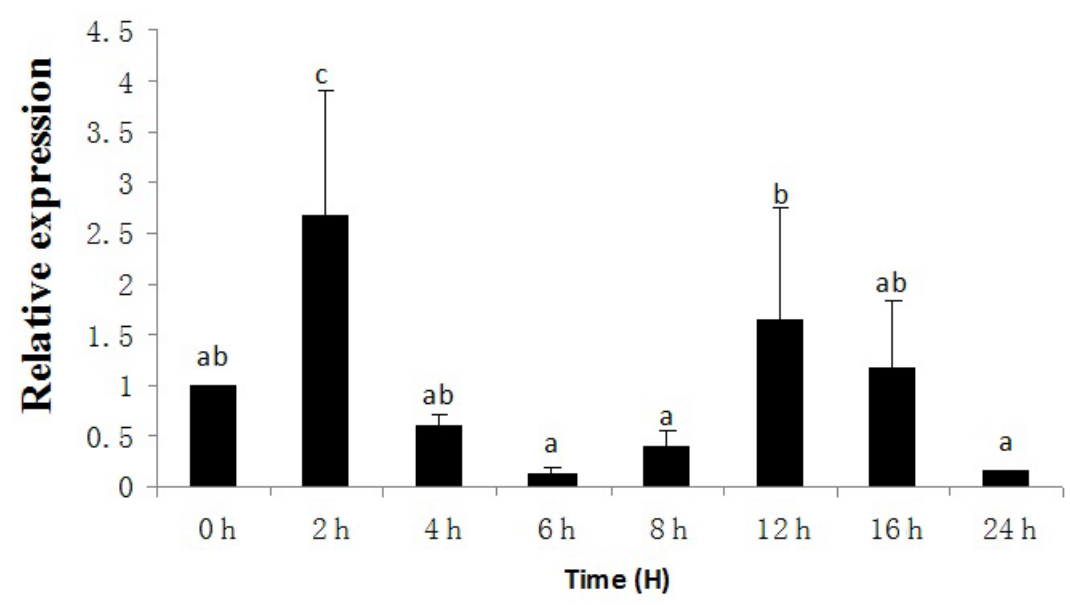

Figure 6. Expression patterns of PmHSP20 mRNA after LPS stimulation. Real time qPCR was performed using the cDNA samples generated from hemocytes $0,2,4,6,8,12,16$, and 24 h post-infection. Pinctada martensii GAPDH was used as an internal reference. Significant difference is indicated by different letters $(\mathrm{P}<0.05)$.

\section{DISCUSSION}

Molluscs are chronically exposed to variable environmental conditions. HSPs act as a buffer by minimizing the biochemical, physiological, and histological stress of the host; therefore, they can function as significant factors to maintain homeostasis across environmental conditions (Li et al., 2010). The present study successfully cloned and characterized the gene encoding HSP20 of $P$. martensii as well as identifying it as a member of the $\alpha$-crystallin family. The protein sequence of PmHSP20 contained two known structure and function domains; namely, a crystallin motif and an HSP20 motif. The result of multiple-alignment of protein sequences of PmHSP20 with other HSP20 orthologs showed that it contained a conserved $\alpha$-crystallin domain, which revealed that PmHSP20 belongs to the sHSP family.

To explore the biological function of PmHSP20 in P. martensii, tissue expression patterns were investigated using real time qPCR. PmHSP 20 was detected in different healthy $P$. martensii organisms with highest expression in the hepatopancreas and lowest in the adductor muscle, hemocyte, gill, and foot (Figure 4). The expression pattern of PmHSP2O in tissues was somewhat similar to previously reported HSP20 expression patterns in the disk abalone (Wan et al., 2012), but different to those previously reported in shrimp (Huang et al., 2008), bloody clam, and razor clam (Bao et al., 2011; Zhang et al., 2013). It has been speculated that different species-or-origin or various tissue functions result in the different expression of sHSPs in tissues. To date, six types of HSP20 in cutworm have been verified to participate in various physiological processes such as thermal stress, development, and 20-hydroxyecdysone induction (Shen et al., 2011).

The expression of HSPs as stress proteins fluctuates when the organism faces variable abiotic stressors and biological stressors such as pathogens and LPS (Li et al., 2010). Generally, the quantity of HSPs increases significantly after bacterial challenge such as has been observed for HSP90 in oyster (Crassostrea hongkongensis) (Fu et al., 2011) and for HSP70 in both bay scallop (Argopecten irradians) (Song et al., 2006) and pearl oyster 
(Pinctada fucata) (Wang et al., 2009). LPS is believed to be an endotoxin because it constitutes the outer leaflet of the outer membrane of most gram-negative bacteria (Wang and Quinn, 2010). LPS has bacterial virulence, inducing a strong response in normal animal immune systems. The response mechanisms after bacterial, viral, and LPS challenge have not been fully revealed, whereas bacterial phagocytosis is generally observed concomitant with the generation of reactive oxygen species (ROS) or oxygen free radicals (Zhang et al., 2010). ROS is an effective defensive factor against bacteria but is simultaneously harmful to the host cell, which could result in protein denaturation or proteotoxicity. It has been suggested that ROS production and the accumulation of denatured proteins in the host cell after bacterial stimulation might motivate HSP expression. The subsequent upregulation of HSPs potentially represents a defense mechanism because HSPs associate with damaged or misfolded proteins in order to restore their original structure (Gao et al., 2008).

To further explore the biological function of PmHSP20 in stress response, its mRNA expression was monitored at different time points after bacterial infection and LPS stimulation. Since hemocytes have been shown to be the primary defense mechanism against pathogens in bivalves (Roberts et al., 2009), the present study utilized them to explore the function of PmHSP20 in the innate immune response. The temporal expression patterns reported here indicate that PmHSP2O expression in hemocytes was significantly elevated after challenge with $V$. harveyi and LPS stimulation. Furthermore, a second, more dramatic upregulation of PmHSP20 expression appeared at $16 \mathrm{~h}$ post infection. Although the exact mechanisms of transcriptional upregulation of PmHSP2O in hemocytes following $V$. harveyi challenge and LPS stimulation are still unknown, the data presented in this manuscript show a correlation between infection and PmHSP20 gene induction. Generally, HSPs increase dramatically in quantity after bacterial or LPS infection. For example, in scallop, HSP22 transcription was found to be upregulated and reached a maximal level at $12 \mathrm{~h}$ after Vibrio challenge, then declined progressively to the original level at $48 \mathrm{~h}$ (Zhang et al., 2009). In the pearl oyster P. martensii, HSP90 expression levels increased significantly and reached a peak at $3 \mathrm{~h}$ in response to LPS challenge, then decreased gradually and returned to the original level at the end of experiment (48 h) (Liang et al., 2015). In the present study, the expression level of PmHSP20 mRNA showed a wave-like pattern after challenge with the biological stressors, which might have resulted from two processes: an acute response related to the immune system and/or a chronic response related to body reparation. This wave-like pattern of HSP expression is similar to previous findings in other species such as HSP20 in clam (Venerupis philippinarum) (Li et al., 2010) and HSP90 in oyster (C. hongkongensis) (Fu et al., 2011). Although the exact transcriptional mechanisms of upregulation of PmHSP20 expression in hemocytes are still unknown, the sequential expression pattern of PmHSP20 might enhance its protective ability against environmental pathogens in $P$. martensii. The different expression profiles between HSPs further elucidated that they belonged to different subtypes of the HSP family and originated from different molluscs. The data presented here begin to elucidate the innate immune system of $P$. martensii by focusing on the role of a conserved protein known to be involved in various stress responses. A better understanding these response mechanisms might alleviate some of the strain on developing aquaculture because diseases caused by bacteria or viruses are still considered as a major constraint to the sustainable development of aquaculture worldwide (Baruah et al., 2010).

In conclusion, PmHSP20 was cloned from the pearl oyster $P$. martensii. Studies indicate that PmHSP2O mRNA is constitutively expressed in all tissues tested. In addition, 
the expression pattern of PmHSP20 under bacterial and LPS challenge indicates that there is a correlation between bacterial exposure and PmHSP20 mRNA levels, therefore suggesting that PmHSP20 might play a significant role in immune defense. Extrapolation of these results might lead to further understanding of the defensive mechanisms marshaled against the wide range of environmental stressors in P. martensii.

\section{ACKNOWLEDGMENTS}

Research supported by the National Natural Science Foundation of China (\#31472306), the Science and Technology Program of Guangdong, China (\#2012A031100010), and the Science and Technology Program of Zhanjiang, China (\#2013A03022).

\section{REFERENCES}

Bao Y, Wang Q, Liu H and Lin Z (2011). A small HSP gene of bloody clam (Tegillarca granosa) involved in the immune response against Vibrio parahaemolyticus and lipopolysaccharide. Fish Shellfish Immunol. 30: 729-733. http://dx.doi.org/10.1016/j.fsi.2010.12.002

Baruah K, Ranjan J, Sorgeloos P and Bossier P (2010). Efficacy of heterologous and homologous heat shock protein 70s as protective agents to Artemia franciscana challenged with Vibrio campbellii. Fish Shellfish Immunol. 29: 733-739. http://dx.doi.org/10.1016/j.fsi.2010.07.011

Bezemer GF, Sagar S, van Bergenhenegouwen J, Georgiou NA, et al. (2012). Dual role of Toll-like receptors in asthma and chronic obstructive pulmonary disease. Pharmacol. Rev. 64: 337-358. http://dx.doi.org/10.1124/pr.111.004622

Jolly C and Morimoto RI (1999). Stress and the cell nucleus: dynamics of gene expression and structural reorganization. Gene Expr. 7: 261-270.

Caspers GJ, Leunissen JAM and de Jong WW (1995). The expanding small heat-shock protein family, and structure predictions of the conserved "a-crystallin domain". J. Mol. Evol. 40: 238-248. http://dx.doi.org/10.1007/BF00163229

Evgrafov OV, Mersiyanova I, Irobi J, Van Den Bosch L, et al. (2004). Mutant small heat-shock protein 27 causes axonal Charcot-Marie-Tooth disease and distal hereditary motor neuropathy. Nat. Genet. 36: 602-606. http://dx.doi. org/10.1038/ng1354

Feder ME and Hofmann GE (1999). Heat-shock proteins, molecular chaperones, and the stress response: evolutionary and ecological physiology. Annu. Rev. Physiol. 61: 243-282. http://dx.doi.org/10.1146/annurev.physiol.61.1.243

Fu D, Chen J, Zhang Y and Yu Z (2011). Cloning and expression of a heat shock protein (HSP) 90 gene in the haemocytes of Crassostrea hongkongensis under osmotic stress and bacterial challenge. Fish Shellfish Immunol. 31: 118-125. http://dx.doi.org/10.1016/j.fsi.2011.04.011

Gao Q, Zhao J, Song L, Qiu L, et al. (2008). Molecular cloning, characterization and expression of heat shock protein 90 gene in the haemocytes of bay scallop Argopecten irradians. Fish Shellfish Immunol. 24: 379-385. http://dx.doi. org/10.1016/j.fsi.2007.08.008

Gusev NB, Bukach OV and Marston SB (2005). Structure, properties, and probable physiological role of small heat shock protein with molecular mass $20 \mathrm{kD}$ (Hsp20, HspB6). Biochemistry (Mosc.) 70: 629-637. http://dx.doi.org/10.1007/ s10541-005-0162-8

Hartl FU (1996). Molecular chaperones in cellular protein folding. Nature 381:571-579. http://dx.doi.org/10.1038/381571a0

Huang PY, Kang ST, Chen WY, Hsu TC, et al. (2008). Identification of the small heat shock protein, HSP21, of shrimp Penaeus monodon and the gene expression of HSP21 is inactivated after white spot syndrome virus (WSSV) infection. Fish Shellfish Immunol. 25: 250-257. http://dx.doi.org/10.1016/j.fsi.2008.06.002

Islamovic E, Duncan A, Bers DM, Gerthoffer WT, et al. (2007). Importance of small heat shock protein 20 (hsp20) C-terminal extension in cardioprotection. J. Mol. Cell. Cardiol. 42: 862-869. http://dx.doi.org/10.1016/j. yjmcc.2007.01.002

Kregel KC (2002). Heat shock proteins: modifying factors in physiological stress responses and acquired thermotolerance. J. Appl. Physiol. 92: 2177-2186. http://dx.doi.org/10.1152/japplphysiol.01267.2001

Landry J, Chrétien P, Lambert H, Hickey E, et al. (1989). Heat shock resistance conferred by expression of the human HSP27 gene in rodent cells. J. Cell Biol. 109: 7-15. http://dx.doi.org/10.1083/jcb.109.1.7

Li C, Wang L, Ning X, Chen A, et al. (2010). Identification of two small heat shock proteins with different response profile 
to cadmium and pathogen stresses in Venerupis philippinarum. Cell Stress Chaperones 15: 897-904. http://dx.doi. org $/ 10.1007 / \mathrm{s} 12192-010-0198-6$

Li H, Liu S, He C, Gao X, et al. (2013). Identification of a small HSP gene from hard clam Meretrix meretrix and its potential as an environmental stress biomarker. Aquat. Biol. 18: 243-252. http://dx.doi.org/10.3354/ab00503

Liang HY, Wang ZX, Lei QN, Huang RL, et al. (2015). Molecular cloning and expression analysis of a pearl oyster (Pinctada martensii) heat shock protein 90 (HSP90). Genet. Mol. Res. 14: 18778-18791. http://dx.doi.org/10.4238/2015. December.28.27

Livak KJ and Schmittgen TD (2001). Analysis of relative gene expression data using real-time quantitative PCR and the 2(-Delta Delta C(T)) Method. Methods 25: 402-408. http://dx.doi.org/10.1006/meth.2001.1262

Mackay DS, Andley UP and Shiels A (2003). Cell death triggered by a novel mutation in the alphaA-crystallin gene underlies autosomal dominant cataract linked to chromosome 21q. Eur. J. Hum. Genet. 11: 784-793. http://dx.doi. org/10.1038/sj.ejhg.5201046

Mahmood T, Safdar W, Abbasi BH and Naqvi SMS (2010). An Overview on the Small Heat Shock Proteins. Afr. J. Biotechnol. 9: 927-949.

Quinlan R (2002). Cytoskeletal competence requires protein chaperones. Prog. Mol. Subcell. Biol. 28: 219-233. http:// dx.doi.org/10.1007/978-3-642-56348-5 12

Roberts S, Goetz G, White S and Goetz F (2009). Analysis of genes isolated from plated hemocytes of the Pacific oyster, Crassostreas gigas. Mar. Biotechnol. (NY) 11:24-44. http://dx.doi.org/10.1007/s10126-008-9117-6

Schlesinger MJ (1990). Heat shock proteins. J. Biol. Chem. 265: 12111-12114.

Selcen D and Engel AG (2003). Myofibrillar myopathy caused by novel dominant negative a B-crystallin mutations. Ann. Neurol. 54: 804-810. http://dx.doi.org/10.1002/ana.10767

Shen Y, Gu J, Huang LH, Zheng SC, et al. (2011). Cloning and expression analysis of six small heat shock protein genes in the common cutworm, Spodoptera litura. J. Insect Physiol. 57: 908-914. http://dx.doi.org/10.1016/j. jinsphys.2011.03.026

Song L, Wu L, Ni D, Chang Y, et al. (2006). The cDNA cloning and mRNA expression of heat shock protein 70 gene in the haemocytes of bay scallop (Argopecten irradians, Lamarck 1819) responding to bacteria challenge and naphthalin stress. Fish Shellfish Immunol. 21: 335-345. http://dx.doi.org/10.1016/j.fsi.2005.12.011

Sun Y and MacRae TH (2005). Small heat shock proteins: molecular structure and chaperone function. Cell. Mol. Life Sci. 62: 2460-2476. http://dx.doi.org/10.1007/s00018-005-5190-4

Thomas X, Campos L, Le QH and Guyotat D (2005). Heat shock proteins and acute leukemias. Hematology 10: 225-235. http://dx.doi.org/10.1080/10245330500093120

Tsvetkova NM, Horváth I, Török Z, Wolkers WF, et al. (2002). Small heat-shock proteins regulate membrane lipid polymorphism. Proc. Natl. Acad. Sci. USA 99: 13504-13509. http://dx.doi.org/10.1073/pnas.192468399

Wan Q, Whang I and Lee J (2012). Molecular and functional characterization of HdHSP20: a biomarker of environmental stresses in disk abalone Haliotis discus discus. Fish Shellfish Immunol. 33: 48-59. http://dx.doi.org/10.1016/j. fsi.2012.03.034

Wang X and Quinn PJ (2010). Lipopolysaccharide: Biosynthetic pathway and structure modification. Prog. Lipid Res. 49: 97-107. http://dx.doi.org/10.1016/j.plipres.2009.06.002

Wang Z, Wu Z, Jian J and Lu Y (2009). Cloning and expression of heat shock protein 70 gene in the haemocytes of pearl oyster (Pinctada fucata, Gould 1850) responding to bacterial challenge. Fish Shellfish Immunol. 26: 639-645. http:// dx.doi.org/10.1016/j.fsi.2008.10.011

Wang Z, Jian J, Lu Y, Wang B, et al. (2011). A tandem-repeat galectin involved in innate immune response of the pearl oyster Pinctada fucata. Mar. Genomics 4: 229-236. http://dx.doi.org/10.1016/j.margen.2011.06.004

Wieske M, Benndorf R, Behlke J, Dölling R, et al. (2001). Defined sequence segments of the small heat shock proteins HSP25 and alphaB-crystallin inhibit actin polymerization. Eur. J. Biochem. 268: 2083-2090. http://dx.doi. org/10.1046/j.1432-1327.2001.02082.x

Wood KL, Voss OH, Huang Q, Parihar A, et al. (2010). The small heat shock protein 27 is a key regulator of CD8+ CD57+ lymphocyte survival. J. Immunol. 184: 5582-5588. http://dx.doi.org/10.4049/jimmunol.0902953

Zhang A, Lu Y, Li C, Zhang P, et al. (2013). A small heat shock protein (sHSP) from Sinonovacula constricta against heavy metals stresses. Fish Shellfish Immunol. 34: 1605-1610. http://dx.doi.org/10.1016/j.fsi.2013.03.005

Zhang L, Wang L, Zhao J, Qiu L, et al. (2010). The responsive expression of heat shock protein 22 gene in Zhikong scallop Chlamys farreri against a bacterial challenge. Aquacult. Res. 41: 257-266. http://dx.doi.org/10.1111/j.13652109.2009.02328.X

Zhao X, Wang Q, Jiao Y, Huang R, et al. (2012). Identification of genes potentially related to biomineralization and immunity by transcriptome analysis of pearl sac in pearl oyster Pinctada martensii. Mar. Biotechnol. 14: 730-739. http://dx.doi.org/10.1007/s10126-012-9438-3

Genetics and Molecular Research 15 (2): gmr.15028799

CFUNPEC-RP www.funpecrp.com.br 